DE DE GRUYTER

OPEN

DOI: 10.1515/jolace-2015-0012

\title{
A comparative self-assessment of difficulty in learning English and German among Sudanese students
}

\author{
Adil Ishag1 \\ Claus Altmayer ${ }^{2}$ \\ Evelin Witruk ${ }^{2}$ \\ ${ }^{1}$ International University of Africa, Sudan \& University of Leipzig, Germany \\ ${ }^{2}$ University of Leipzig, Germany \\ adilishag@uni-leipzig.de
}

\begin{abstract}
It is generally assumed that self-assessment plays a profound role in autonomous language learning and, accordingly, leads to learner independency. It encourages learners to prospect their own language learning processes and provides them with feedback of their learning progress. Self-assessment also raises the awareness of learners' individual needs among both students and teachers alike and will therefore contribute to the development of the whole learning process.

The purpose of the current study is to explore and compare - through self-assessment - the level of perceived difficulty of the overall foreign language learning and language skills among Sudanese students enrolled at the English and German language departments respectively, at the University of Khartoum in Sudan. A representative sample composed of 221 students from the two departments have been asked to self-evaluate and rate the overall language difficulty and areas of difficulty in language skills, as well as their own language proficiency.

The results indicate that German language is relatively rated as a difficult language in comparison to the English language and that German grammar was also rated as more difficult. However, students rated the pronunciation and spelling of German language as easier than in English language. Concerning the language skills, reading and speaking skills were reported as more difficult in German, whereas writing and listening tend to be easier than in English. Finally, students' academic achievements have been self-reported.
\end{abstract}

Keywords

self-assessment, learning difficulties, English language, German language

\section{Introduction}

Self-assessment as defined by Boud and Falchikov (1989) refers to the involvement of learners in making judgments about their own learning, particularly about their achievements and the outcomes of their learning. The term self-assessment is used interchangeably along with related terms such as selfrating, self-evaluation, self-testing, and self-appraisal. As Chen (2008) pointed out, the inadequacies of traditional assessment attracted the attention of scholars and triggered a shift toward alternative assessment. Theses alternative self-assessment methods include performance assessment, portfolio assessment, students' self-assessment, peer assessment, and so forth. Self-assessment could generally be contextualized within the progressive shift from the traditional, structural, teacher-centered approach to the humanistic learner-centered approach in learning in general, and second language learning more specifically. This reflects the substantial attention directed over the past two decades towards self-assessment in various educational contexts, including foreign and second language education and the growing interest in self-regulated learning, which is a major component of learnercentered instruction (Boud, 1995; Huba \& Fred, 2000; Dann, 2002; Dickinson, 1987). 
Self-assessment can be used for a variety of purposes such as placement, diagnosis, evaluation, and feedback within the foreign and second language learning process. There are practically different instruments used for self-assessment. Harrington (1995) for example used three different selfassessments. One is simply a listing of abilities with definitions and directions to indicate those areas learners feel are their best or strongest. The second approach is to apply a Likert scale to a group of designated abilities (in comparison to others of the same age, my art ability is excellent, above average, average, below average, or poor). Another approach is to provide different examples of the ability's applications on which individuals rate their performance level from high to low, and subsequently these are summed to obtain a total score.

\section{Self-assessment as a learning tool}

Assessment is currently represented as a tool for learning (Arter, 1996; Dochy \& McDowell, 1997). Self-assessment is therefore considered as a diagnostic and learning tool at the same time, it could be used to evaluate and diagnose areas of difficulties in language learning as well as a learning strategy. It is assumed that human beings are naturally capable of self-reflection and introspection about their behavior and they actually practice it regularly in different daily domains, which could not easily be assessed by external assessors. Moreover, self-assessment plays a crucial role in self-regulated learning, which is central to the way students become independent learners (Wenden, 2001). Self-regulated learners monitor their own performance and evaluate their progress and accomplishments (O'Malley \& Valdez, 1996). In this regard, Chamot and O'Malley (1994) point out that self-rating requires the student to exercise a variety of learning strategies and higher order thinking skills that not only provide feedback to the student but also stimulate revision strategies and provide direction for future learning. Moreover, since self-assessment involves both reflection and evaluation of one's own performance, it is intended to give students an opportunity to feel a sense of control over their own actions and to develop positive attitudes towards learning, thus increasing motivation (Paris \& Paris, 2001). Additionally, selfassessment - which requires critical reflection and introspection - leads learners to develop critical, analytical skills, and a better self-awareness. Ushioda (1996) asserts that by being treated as equal partners in the learning and assessment processes, their self-esteem and self-respect are enhanced and they develop a positive self-concept since their opinions are valued. This has, in turn, a positive impact on their motivation which constitutes a key feature of successful learners.

Furthermore, self-assessment has many advantages such as learner involvement in the learning process, learner autonomy, increased motivation, development of study skills, and a lifelong learning (Angelo \& Cross, 1993; Wenden, 2001; Geeslin, 2003). However, Saito (2005) postulated that the empirical studies on the effectiveness of self-assessment have produced varying results which have made test administrators and teachers sceptical about implementing self-assessment in the assessment of second language ability. This has in turn raised issues of reliability and validity of self-assessment. In this regard, there are a number of factors that might be responsible for the variability in self-assessment results. These factors can be related to the domain or skills being assessed, students' individual characteristics, and the formulation of the items and questions posed. Regarding the first factor which implies variation on self-evaluation accuracy according to the assessed domain or skill, Ross (1998) conducted a meta-analysis of validation studies on self-assessment and found that self-assessing one's receptive skills, such as listening and reading, has been found to be more accurate than for productive skills such as speaking and writing. This implies that language domains are distinct and thus performance in the four domains is strongly correlated. However, Liu and Costanzo (2013) pointed out that this is not to the degree that a measure of one can adequately substitute for a measure of another. Although studies have found a conflicting set of results, recent research has generally concluded that language skill entails multiple components - a prominent general ability common to all domains, as well as specific abilities that are unique to each language skill. Moreover, studies in the field of selfassessment in foreign language learning have mainly investigated the correlation between teacher 
assessment and students' self-assessment, to investigate to which extent self-rating matches the final assessment conducted by teachers.

\section{Contrastive analysis and language learning difficulties}

Contrastive Analysis (CA) as a discipline in the field of second language acquisition and applied linguistics is associated with the English-Spanish bilingual linguist Lado (1957), who has tried to explain why some features or elements of a target language are more difficult to acquire than others. Contrastive analysis has been initiated under the umbrella of structural linguistics and behaviourism, which is a general theory of learning that views learning in general and language learning consequently as a habit formation, which could be reinforced through stimulus-response.

Contrastive Analysis hypothesized that the structure of the first language (L1) affects the acquisition of the second language (L2). Lado (1957) explained in his book Linguistics across Cultures that "the plan of the book rests on the assumption that we can predict and describe the patterns that will cause difficulty in learning, and those that will not cause difficulty, by comparing systematically the language and the culture to be learned with the native language and culture of the student" (p. vii). Thus, difficulty in learning and mastering certain structures in a second language depends on the differences between the learner's mother tongue and the target language intended to be learned. On the other hand, similar elements were assumed to be easy to learn.

In terms of predictability, Contrastive Analysis Hypotheses (CAH) can be classified into three hypotheses, namely strong, weak and moderate version. In its strongest version, Lado (1957) claimed that individuals tend to transfer the forms and meanings and the distribution of forms and meanings of their native language and culture to the foreign language and culture. It was further claimed that all errors made in the second language could be attributed to interference by the first language. The notion of "transfer" means carrying over the habits of the learner's mother-tongue into the second language (Corder, 1971). Therefore, similarities between the first and second language are assumed to facilitate the process of second language acquisition. By contrast, differences are supposed to cause learning difficulties and represent as the main source of errors. Hence, the more a foreign language differs from a learner's mother-tongue, the harder it is predicted to be acquired.

In the weak version, the emphasis has switched from the predictive power of relative difficulty to a kind of explanation for observable errors (Byung-gon, 1992). In this version, errors are examined and explained after they have been produced by second language learners. It further hypothesized that errors come from lack of enough knowledge in the second language.

The moderate version as proposed by Oller and Ziahosseiny (1970), based on their study of spelling errors in English as a second language, stated that "the categorization of abstract and concrete patterns according to their perceived similarities and differences is the basis for learning; therefore, wherever patterns are minimally distinct in form or meaning in one or more system confusion may result". Similarly, Brown (1987) explained that interference causes learning problem when the two learned items are similar, whereas a little interference occurs if the two items are distinct.

\section{Methodology}

The sample of the study composed of 221 Sudanese undergraduate students studying English and German in the Faculty of Arts, University of Khartoum. 148 participants out of 273 were drawn from the department of English language, and 73 students out of 79 from the department of German language have participated in the survey, which was a highly representative sample concerning the total available population, especially in the department of German language. The sample size of the German department was considerably smaller than the sample size drawn from the English department, and this was due to the actual smaller number of students majoring in German language.

The mother tongue of almost all participants was Sudanese Arabic and they were majoring in either German or English along with another discipline such as: French, Chinese, Russian, Arabic and 
Linguistics. The data collection was carried out in June - July 2013 at the department of English language and department of German language respectively, at the Faculty of Arts, University of Khartoum. Participants were asked to indicate the level of overall language difficulty in general and for each language skill separately, as well as self-rating their language achievement. The obtained quantitative data have been tabulated, coded and statistically analyzed.

\section{Results and discussion}

Before presenting the findings of the current study, it will be meaningful to firstly present one of the ranking lists in the literature, to give a general background on ranking learning difficulties of foreign languages. The Foreign Service Institute (FSI) of the US Department of State has created an approximate difficulty ranking list for a number of foreign languages for an English native speaker, based on the length of class hours it takes to achieve a professional proficiency level. As shown in the ranking below (Table 1), languages in the first category are closely related to English. Although German and English belong to the same language family, German in the second category is still considered as a relatively difficult language for an English speaking learner, which requires extra 150 class hours more than French or Spanish, for example, to reach the same proficiency level. Languages in the third category are linguistically or culturally different from English, while languages in the fourth category significantly differ from English in terms of linguistic or cultural aspects. Finally, languages which are totally different from English and exceptionally difficult for English native speakers are incorporated in the fifth category.

Table 1: Classification of languages learning difficulty by The Foreign Service Institute (FSI)

\begin{tabular}{|l|l|l|l|l|l|}
\hline Categories & $\begin{array}{l}\text { Category I: 600 } \\
\text { hours }\end{array}$ & $\begin{array}{l}\text { Category II: } \\
750 \text { hours }\end{array}$ & $\begin{array}{l}\text { Category III: } \\
900 \text { hours }\end{array}$ & $\begin{array}{l}\text { Category IV: } \\
1100 \text { hours }\end{array}$ & $\begin{array}{l}\text { Category } \\
2200 \text { hours }\end{array}$ \\
\hline Examples & $\begin{array}{l}\text { Afrikaans, } \\
\text { Dutch, French, } \\
\text { Italian }\end{array}$ & German & $\begin{array}{l}\text { Indonesian, } \\
\text { Malaysian, } \\
\text { Swahili }\end{array}$ & $\begin{array}{l}\text { Amharic, } \\
\text { Czech, Greek, } \\
\text { Turkish }\end{array}$ & $\begin{array}{l}\text { Arabic, } \\
\text { Chinese, } \\
\text { Japanese, } \\
\text { Korean }\end{array}$ \\
\hline
\end{tabular}

The findings of the study can be summarized and presented as follows:

Table 2: Overall language learning difficulty

\begin{tabular}{|l|l|l|l|l|l|l|}
\hline $\begin{array}{l}\text { Level of } \\
\text { Difficulty }\end{array}$ & $\begin{array}{l}\text { Very } \\
\text { difficult }\end{array}$ & Difficult & $\begin{array}{l}\text { Moderately } \\
\text { difficult }\end{array}$ & Easy & Very easy & Total \\
\cline { 1 - 3 } Language & $.7 \%$ & $4.7 \%$ & $49.3 \%$ & $31.8 \%$ & $13.5 \%$ & $100 \%$ \\
\hline English & $4.1 \%$ & $21.9 \%$ & $65.8 \%$ & $8.2 \%$ & $.0 \%$ & $100 \%$ \\
\hline German &
\end{tabular}

As for the results concerning the overall level of language learning difficulty (Table 2), it is clear that students of the German department have rated German language as more difficult than the students of the English department. None of the students has considered German as a very easy language, while 13.5\% have rated English as a very easy language. However, there were many students who rated German as a moderately difficult language than English. This result might be attributed to the fact that most students just started to study at the university without any previous background, whereas English is a compulsory subject at Sudanese schools from the fifth class, and thus this previous background and long exposure to the English language makes it easier than the newly introduced German. Additionally, German language is classified as a relatively difficult language even for an English native speaker, more 
than French or Italian which only take 600 class hours to reach a proficiency level, while achieving the same level in German requires about 750 class hours.

Table 3: Difficulty of language domain

\begin{tabular}{|l|l|l|l|l|l|}
\hline $\begin{array}{l}\text { Domain of } \\
\text { Difficulty }\end{array}$ & Grammar & Pronunciation & Spelling & All equal & Total \\
\cline { 1 - 3 } Language & & $27.7 \%$ & $14.2 \%$ & $20.3 \%$ & $100 \%$ \\
\hline English & $37.8 \%$ & $19.2 \%$ & $4.1 \%$ & $12.3 \%$ & $100 \%$ \\
\hline German & $64.4 \%$ & &
\end{tabular}

Regarding the difficulty of language domain, the results above (Table 3) show that German grammar is more difficult than English grammar, which might be explained as Rogers (1987) stated that "in the acquisition of German as a foreign language, grammatical gender has often been viewed as a problem for both learners and teachers alike". There are three grammatical genders in German for masculine, feminine and neutral, these genders change according to grammatical case and number, compared to only one fixed gender in English or in Arabic, which is the mother language of the participants. As Durrell (1977) points out, German determiners and adjectives have sixteen possible slots in their full matrix (four grammatical cases, three genders in the singular, and additionally the plural). Additionally, German has difficult syntactical features, with its four cases, namely nominative, accusative, dative and genitive for all nouns, pronouns and adjectives, thus it is considered as a highly inflectional and derivational language compared to English.

Table 4: Difficulty of language skill

\begin{tabular}{|l|l|l|l|l|l|}
\hline $\begin{array}{l}\text { Difficulty of } \\
\text { Skill }\end{array}$ & Reading & Writing & Speaking & Listening & Total \\
\cline { 1 - 5 } Language & & & & & \\
\hline English & $4.0 \%$ & $25.7 \%$ & $44.6 \%$ & $25.7 \%$ & $100 \%$ \\
\hline German & $8.2 \%$ & $9.6 \%$ & $68.5 \%$ & $13.7 \%$ & $100 \%$ \\
\hline
\end{tabular}

Concerning the language skills as shown above in Table 4, speaking or communication skill is considered as the most difficult skill in both English and German, which indicate communication difficulties among students, due to lack of communication opportunities in an Arabic speaking community. However, the students of German language have relatively more communication problems than their counterparts at the English department; this might also be attributed to the grammatical and syntactical complexity of the German language, which might impede the fluency of speaking. As shown in the table, students have twice more difficulties in reading German than reading in English, which could also be attributed to the early exposure and familiarity with the English language during previous schooling, while reading in German is relatively recently introduced at the university level without any previous background. Additionally, German language has a lot of long and compound words, which require much effort to analytically decipher and grasp the meaning of the phrases.

However, listening and writing in German have been equally rated as easier than listening and writing in English. This result could be explained in terms of the simplicity of the German orthography, which is more consistent, logical and rule-governed than in English. This will in turn facilitate the writing process and the listening comprehension, because the way the words are written in German is mostly identical to their pronunciation. English orthography, on the other hand, is quite non-systematic with many silent letters and exceptions. This may result in more writing errors in writing English than in German, and be also responsible for a greater listening comprehension difficulty in English than in German, which is relatively clearly pronounced exactly as it is written. 
Table 5: Self-assessment of language achievement

\begin{tabular}{|l|l|l|l|l|l|}
\hline \multicolumn{1}{|l|}{ Self-rating } & Excellent & Very Good & Good & Pass & Total \\
\cline { 1 - 5 } Department & & & & & \\
\hline English & $13.5 \%$ & $37.2 \%$ & $45.3 \%$ & $4.1 \%$ & $100 \%$ \\
\hline German & $11.0 \%$ & $50.7 \%$ & $37.0 \%$ & $1.4 \%$ & $100 \%$ \\
\hline
\end{tabular}

Regarding the self-rating, the students have been asked to estimate their own language achievement. As shown above (Table 5), most students have rated their language achievements as very good or good in both departments, with more students of German having very good achievements than their counterparts of English language. Self-assessments may not exactly reflect their actual language proficiency, because students might tend to overestimate or underestimate their proficiency level as a result of many factors that might question the reliability of such self-assessment.

\section{Conclusions}

The skill of self-assessment is very important in the development of lifelong learning and the development into autonomous individuals. Accordingly, the current study attempted to explore the learning difficulties among Sudanese university students studying English and German language respectively, in order to identify which language have the most linguistic features and therefore relatively more difficult to learn. Based on the students' self-assessment of the overall learning difficulty as well as domain and language skill relative difficulty in the target foreign language, one might conclude that learning German is tend to be more difficult than learning English. However, there are some differences between the two languages in term of relative learning difficulty according to the assessed language domain and skill.

The self-assessment of foreign language learning difficulty in this study is considered from the aspect of Arabic-speaking students. Thus, the comparison between the two languages is not comprehensive and therefore the findings might not be generally extended into other learning contexts. This indicates that one criterion of difficulty in learning a foreign language is the degree to which the language differs from the students' native language. On the other hand, language learning is too complex to be generally described as easy or difficult to learn, because each language comprises many linguistic features and domains, where some of them are easy and other elements are quite difficult. Accordingly, the current study might be useful in setting a preliminary general framework for relative difficulty of foreign language learning, and pave the way for more in-depth further studies and investigations that assess different aspects and factors involved in assessing the relative difficulty in foreign language learning.

\section{References}

Angelo, T. A. \& Cross, K. P. (1993). Classroom Assessment Techniques: A Handbook for College Teachers. San Francisco: Jossey-Bass Publishers.

Arter, J. (1996). Using Assessment as a Tool for Learning. In Blum, R. \& Arter, J. (Eds.), Student Performance Assessment in an Era of Restructuring (p. 1-6). Alexandria, VA: ASCD.

Boud, D. (1995). Enhancing Learning Through Self Assessment. London: Kogan Page.

Boud, D. \& Falchikov, N. (1989). Quantitative Studies of Self-assessment in Higher Education: A Critical Analysis of Findings. Higher Education, 18(5), 529-549.

Brown, H. D. (1987). Principles of Language Learning and Teaching. (2nd ed.), New Jersey: Printice-Hall. Byung-gon, Y. (1992). A Review of The Contrastive Analysis Hypothesis. Retrieved from: http://fonetiks.info/bgyang/db/92cah.pdf

Chamot, A. U. \& J. M. O’Malley. 1994. The CALLA Handbook: Implementing the Cognitive Language Learning Approach. Reading, MA: Addison Wesley. 
Chen, Y. M. (2008). Learning to Self-assessment Oral Performance in English: A Longitudinal Case Study. Language Teaching Research, 12(2), 235-262.

Corder, S. P. (1971). Idiosyncratic Dialects and Errors Analysis. International Review of Applied Linguistics in Language Teaching, Vol 9.

Dann, R. (2002). Promoting Assessment as Learning: Improving the Learning Process. New York: Routledge.

Dickinson, L. (1987). Self-Instruction in Language Learning. Cambridge. Cambridge University Press.

Dochy, F. J. R. S. \& McDowell, L. (1997). Assessment as a Tool for Learning. Studies in Educational Evaluation, 23(4), 279-298.

Durrell, M. (1977). Zur Morphologischen Struktur der Deutschen Nominalphrase. Deutsch als Fremdsprache, 14(1), 44-52.

Geeslin, K. L. (2003). Student Self-assessment in the Foreign Language Classroom: The Place of Authentic Assessment Instruments in the Spanish Language Classroom, Hispania, 86(4), 857-868.

Harrington, T. F. (1995). Assessment of Abilities. US: North Carolina.

Huba, M. E. \& Freed, J.E. (2000). Learner-centered Assessment on College Campuses. Needham Heights, MA: Allyn and Bacon.

Lado, R. (1957). Linguistics Across Cultures. Ann Arbour, Michigan: University of Michigan Press.

Liu, J., \& Costanzo, K. (2013). The Relationship among TOEIC Listening, Reading, Speaking, and Writing Skills. In D. E. Powers (Eds.) The Research Foundation for TOEIC Test: A Compendium of Studies. Vol. 2, Princeton, NJ: Educational Testing Service.

Oller, J. W. \& Ziahosseiny, S. M. (1970). The Contrastive Analysis Hypothesis and Spelling Errors. Language Learning, Vol. 20.

O’Malley, J. M. \& Valedez Pierce, L. (1996). Authentic Assessment for English Language Learners: Practical Approaches for Teachers. New York: Addison-Wesley Publishing Company.

Paris, S. G. \& Paris, A. H. (2001). Classroom Applications of Research on Self-regulated Learning. Educational Psychology, 36(2), 89-101.

Rogers, M. (1987). Learners' Difficulties with Grammatical Gender in German as a Foreign Language. Applied Linguistics, Vol. 8(1), Oxford: Oxford University Press.

Ross, S. (1998). Self-assessment in Second Language Testing: A Meta-analysis and Analysis of Experimental Factors. Language Testing, 15(1), 1-20.

Saito, Y. (2005). The Use of Self-assessment in Second Language Assessment. Working Papers in TESOL and Applied Linguistics. from www.tc.columbia.edu/academic/tesol/WJFiles/pdf/Saito_Forum.pdf

Ushioda E. (1996). Learner Autonomy 5: The Role of Motivation. Dublin: Authentik.

Wenden, A. L. (2001). Metacognitive Knowledge in SLA: The Neglected Variable. In M. P. Breen (Ed.), Learner Contributions to Language Learning (p. 44-64). Harlow, England: Longman.

\section{Contact}

Adil Ishag

Faculty of Education

International University of Africa, Sudan

University of Leipzig, Germany

adilishag@uni-leipzig.de 